\title{
CASE REPORT OF SPONDYLOEPIPHYSEAL DYSPLASIA SECONDARY TO CONGINETAL HYPOTHYROIDISM
}

\author{
Jhatoth Venkateshwarlu1, Tandra Venkateshwararao², K. Ramkumar Reddy³, C. H. Srinivas Yadav ${ }^{4}$
}

\section{HOW TO CITE THIS ARTICLE:}

Jhatoth Venkateshwarlu, Tandra Venkateshwararao, K. Ramkumar Reddy, C. H. Srinivas Yadav. "Case Report of Spondyloepiphyseal Dysplasia Secondary to Congenital Hypothyroidism". Journal of Evolution of Medical and Dental Sciences 2014; Vol. 3, Issue 30, July 28; Page: 8308-8312, DOI: 10.14260/jemds/2014/3046

ABSTRACT: BACKGROUND: Spondyloepiphyseal dysplasia as a sign of untreated congenital hypothyroidism is rare nowadays due to implementation of neonatal screening and increased awareness of pediatricians to detect hypothyroidism earlier. But neonatal screening is not routinely done in the developing countries. Congenital hypothyroidism is still unrecognized in some parts of developing world. OBJECTIVE: To describe the clinical, radiographic features and to stress the importance of screening of hypothyroidism during infancy and childhood and its current management. METHODS: Detailed history, physical examination and investigations. CONCLUSION: This report underscores the importance of detailed family history and physical examination in the diagnosis of spondyloepiphyseal dysplasia due to untreated congenital hypothyroidism, which was not screened for hypothyroidism during neonatal life. Being a treatable cause, hypothyroidism should always be considered as differential diagnosis of spondyloepiphyseal dysplasia, especially if the patient belongs to the developing world.

KEYWORDS: congenital, hypothyroidism, neonatal screening, Spondyloepiphyseal dysplasia, treatable cause.

INTRODUCTION: Hypothyroidism is a syndrome encountered in infants and children, resulting from a deficiency of the thyroid hormones thyroxine and triiodothyronine, either during fetal life (cretinism) or early childhood (juvenile myxedema or juvenile hypothyroidism).

The deficiency may be primary, caused by disease of the thyroid gland, or secondary, caused by lack of thyroid-stimulating hormone (TSH) produced by the pituitary gland. The major target sites are the growth plates and epiphyses, best-demonstrated in the hands and the hips. ${ }^{1}$

The key symptoms and signs include lethargy, constipation, an enlarged tongue, abdominal distension, and dry skin. The manifestations are typically less severe when the deficiency occurs in early childhood as an acquired disease than when it is congenital.

Thyroid hormone is very important in regulating bone growth and maturation. In patients with hypothyroidism, enchondral bone formation is disturbed. The skeleton is immature for the infant's chronologic age. ${ }^{2}$

CASE REPORT: A 19 yr. old boy was presented to the orthopedic outpatient department with pain over the left hip.

On asking for history his mother told the boy has pain in the both hip joints at irregular periods frequently. For which he is taking pain subsiding medication.

He is 1 st child of consanguineous marriage delivered by normal labor. The information about thyroid status during infancy was not available. 


\section{CASE REPORT}

He has achieved delayed milestones, for which his mother take him to a pediatrician where he received some medication about which details were not known. He didn't mention about the disease.

On physical examination boy was short stature, with dull facial expression, puffiness of face, protruding tongue, short and webbed neck, discolored hair, protruding abdomen everted umbilicus, shiny skin on the legs, bilateral pedal edema which was non-pitting type, small testis, low intelligence not responding to commands.

Gait was waddling gait.

On examination of left hip joint there were no visible abnormalities, no deformities no local raise of temperature and both hip are tender. All movements are painful and restricted. No distal neurovascular deficits.

\section{Clinical presentation:}
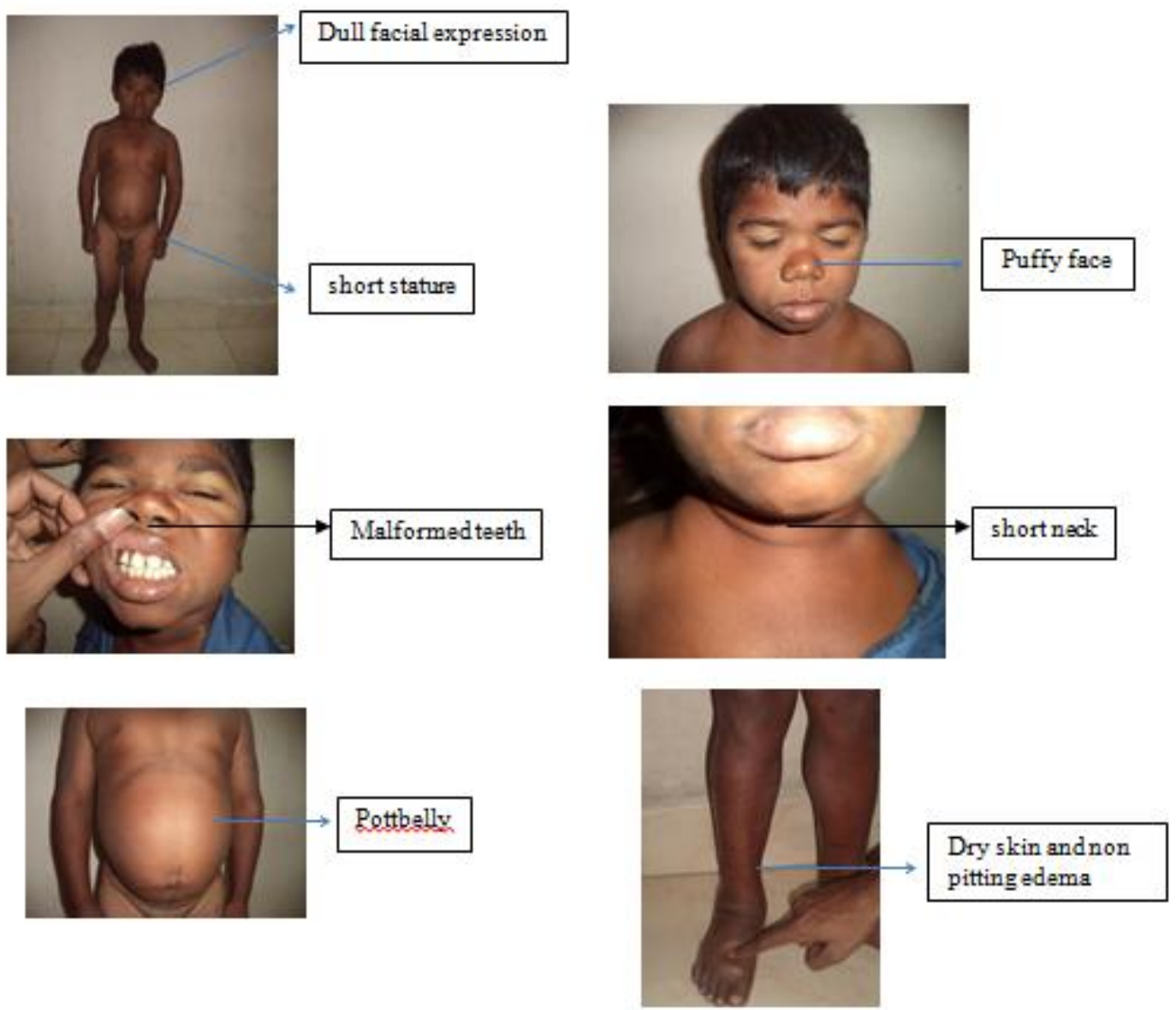

X-ray of pelvis with both hip joints was ordered. Which shows the epiphyseal fragmentation and delayed bone age compared to the chronological age. Then x-ray of both wrist and hands ordered to know the bone age surprisingly they were also shown the fragmented epiphysis.

The diagnosis is thought to be multiple epiphyseal dysplasia and clinical features suggesting hypothyroid state complete thyroid profile ordered, TSH levels are high and T3, T4 levels are low. 
Further radiographic evaluation done, showing multiple changes in the skeletal system which also pointing towards hypothyroid changes.

They are:
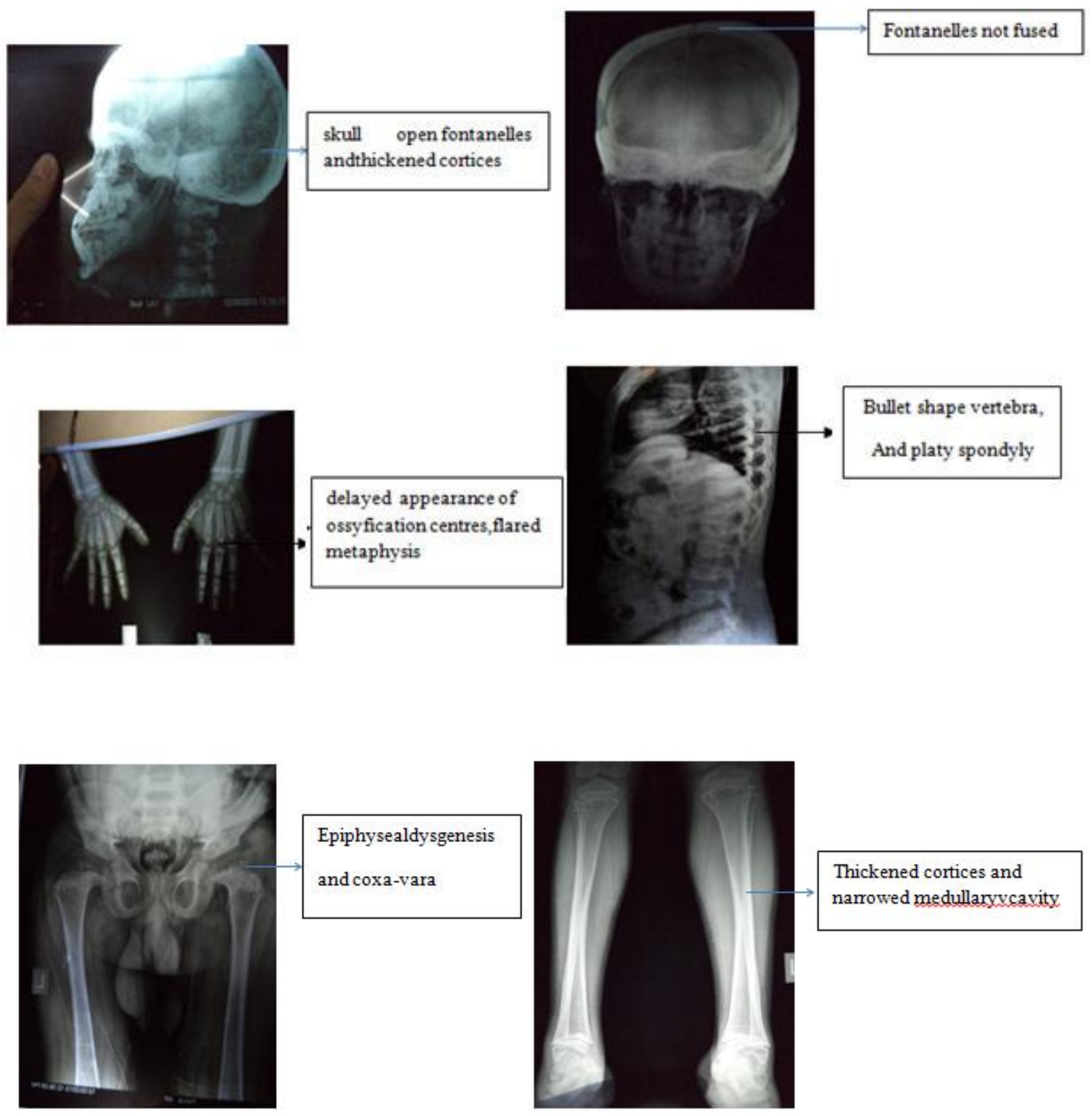

Laboratory investigations: Thyroid investigations revealed free T3: $0.14 \mathrm{ng} / \mathrm{ml}$; T4: $0.20 \mu \mathrm{g} / \mathrm{dl}$, TSH: $64.49 \mu \mathrm{IU} / \mathrm{ml}$.

Treatment was started with thyroid hormone replacement therapy the changes gradually begin reverted and even height also improved. 
DISCUSSION: Spondyloepiphyseal dysplasia (SED) is a descriptive term for a group disorders with primary involvements of vertebrae and epiphyseal centres resulting in a short-trunk disproportionate dwarfism. Spondylo refers to spine, epiphyseal refers to growing ends of bones and dysplasia refers to abnormal growth. ${ }^{3}$ Thyroid hormone deficiency may be congenital or acquired.

The degree of deficiency, age at onset, and duration of the deficiency are all factors that determine the severity of disease. Hypothyroidism is fairly common, with an incidence of 1 per 4000 newborns ${ }^{2}$. Congenital hypothyroidism, previously known as cretinism, is characterized by dwarfism and mental retardation. It is more common in girls than in boys. ${ }^{2}$

Epiphyseal ossification abnormalities occurring in childhood hypothyroidism began to appear in medical literature by 1909.0nly those epiphyseal centers which would normally undergo ossification at the time of the hypothyroidism showed the dysgenesis. Disappearance of epiphyseal dysgenesis was noted within a year or two after starting therapy.

Appearance of the epiphyses is delayed, and they look irregular and fragmented, which in childhood resembles what is seen in Perthes' disease or multiple epiphyseal dysplasia. Epiphyseal dysgenesis was the term used by Reilly and Smyth to describe the ossific nuclei.

The physis may be irregular and widened, similar to the radiographic picture in rickets. The bone age of the patient is delayed. The long bones are abnormally widened as a result of normal intramembranous bone formation in the context of disturbed endochondral ossification.

The head appears large. Radiographically, ossification of the skull is retarded and the base of the skull is shortened. The sella turcica may be enlarged. Closure of the fontanelles is delayed. A delay in the development of normal dentition is common.

Spinal radiographs show a tendency toward thoracolumbar kyphosis. The vertebral body of L2 is wedge shaped and the anterior margin is beaked. L1 and L3 may have a similar appearance. The bony end-plates are convex.

Osteosclerosis develops in some patients as a result of hyper calcemia. Radiographs in these patients show transverse radiopaque bands in the metaphyseal areas and thickened cortices. Metastatic calcification can occur.

Treatment begins immediately on diagnosis. Hormone replacement therapy with thyroxine is initiated and carefully monitored. With hormonal replacement therapy, the pubertal growth spurt is normal, and adult height is within normal limits. Long-term thyroxine replacement therapy has not been shown to decrease bone mass and lead to osteopenia. Prompt treatment results in normal intellectual development. ${ }^{2}$

As a complication in the pelvis the incidence of slipped capital femoral epiphysis is increased ${ }^{4}$.

\section{REFERENCES:}

1. Orthopaedic imaging: a practical approach, $4^{\text {th }}$ edition chapter 30 miscellaneous metabolic and endocrine disorders.

2. Tachdjian's pediatric orthopedics, $4^{\text {th }}$ edition, Chapter 32 - Metabolic and Endocrine Bone Diseases Hypothyroidism page 1940.

3. Campbell's orthopaedics, $12^{\text {th }}$ edition chapter 32 osteochondrosis or epiphyseal and other miscellaneous affections page 1880. 


\section{CASE REPORT}

4. Sutton: text book of radiology and imaging $7^{\text {th }}$ edition chapter 42 metabolic and endocrine disorders of the bone page 1359.

5. Lovell and winter's paediatric orthopaedics: chapter 8.

\section{AUTHORS:}

1. Jhatoth Venkateshwarlu

2. Tandra Venkateshwararao

3. K. Ramkumar Reddy

4. C. H. Srinivas Yadav

\section{PARTICULARS OF CONTRIBUTORS:}

1. Associate Professor, Department of Orthopaedics, Kakatiya Medical College, MGM Hospital, Warangal. Telangana.

2. Professor and HOD, Department of Orthopaedics, Kakatiya Medical College, MGM Hospital, Warangal. Telangana.

3. Associate Professor, Department of Orthopaedics, Kakatiya Medical College, MGM Hospital, Warangal. Telangana.

4. Post Graduate, Department of Orthopaedics, Kakatiya Medical College, MGM Hospital, Warangal. Telangana.

\section{NAME ADDRESS EMAIL ID OF THE CORRESPONDING AUTHOR:}

Dr. Jhatoth Venkateshwarlu M. S, Department of Orthopedics, H. No. 2-9-81/1, Swarna Kalamandir Road, Jangaon District, Warangal-506167, Telangana.

Email: jhatoth@gmail.com

Date of Submission: 14/07/2014.

Date of Peer Review: 15/07/2014.

Date of Acceptance: 21/07/2014.

Date of Publishing: 22/07/2014. 